\title{
O dinheiro do espírito: idealismo e crítica da economia política no jovem Marx
}

\author{
The money of spirit: idealism and the critique of political economy \\ in the young Marx
}

Bruno Klein Serrano

bruno.klein@hotmail.com

(Universidade de São Paulo, São Paulo, Brasil)

\begin{abstract}
Resumo: 0 objetivo do artigo é apresentar uma interpretação do estatuto teórico da crítica da economia política nos escritos de juventude de Marx. Para isso, privilegia os assim chamados Manuscritos econômicofilosóficos e os Excertos do livro de James Mill "Éléments d'économie politique". Nesse contexto, o artigo procura esclarecer a relação mutuamente constitutiva que Marx via entre a economia política, o idealismo de Hegel e a sociedade capitalista. Sustenta-se a ideia de que essa relação define o sentido teórico geral de seu projeto de crítica da economia, bem como precisa as noções de crítica e dialética nela empregadas.
\end{abstract}

Palavras-chave: Marx; crítica da economia política; idealismo; dialética.

\begin{abstract}
The aim of the article is to present an interpretation of the theoretical status of the critique of political economy of the young Marx. For this, it privileges the socalled Economic-philosophical manuscripts and Excerpts from the James Mill's Book "Éléments d'économie politique". In this context, this article seeks to clarify the mutually constitutive relation that Marx saw between political economy, Hegel's idealism and the capitalist society. It is sustained the idea that this relation defines the general theoretical meaning of the author's project of critique of political economy, as well as the notions of critique and dialectics employed there.
\end{abstract}

Keywords: Marx; critique of political economy; idealism; dialectics.

\section{Introdução}

Um dos aspectos da obra de Marx que ganham cada vez mais relevo no debate contemporâneo é a sua elaboração de uma crítica da economia política. Nesse contexto, costuma-se restringir o foco das atenções às formulações maduras, a partir de seu período londrino. Por essa razão, os textos de juventude, considerados excessivamente filosóficos, com frequência aparecem como um material estranho àquela elaboração. Essa circunstância pode levar ao rompimento das vias de 
comunicação entre filosofia, sociedade e a crítica da economia política na origem do projeto teórico de Marx. No presente artigo, contudo, argumento que esses três campos de investigação são interna e necessariamente conectados já nas primeiras tentativas do autor de construir sua crítica da economia. Nesse sentido, privilegio os Manuscritos econômico-filosóficos e os Excertos do livro de James Mill - ambos manuscritos, escritos em 1844 e nunca publicados em vida pelo autor, registrando seus primeiros contatos com o pensamento econômico moderno. ${ }^{1}$

$\mathrm{Na}$ primeira parte do artigo, revisito preliminarmente o significado da crítica de Feuerbach a Hegel e a sua proposta de reforma da filosofia. Em seguida, delimito o impacto dessas concepções sobre o jovem Marx no contexto de seu confronto inicial com a economia política. Na segunda parte, discuto os conceitos de abstração, forma e universalidade em Marx. Na terceira parte, procuro aprofundar a relação entre economia e idealismo, esclarecendo de que modo e em que bases Marx reabilita a dialética como crítica da sociedade capitalista. Afinal, faço uma consideração geral sobre o sentido da interpretação proposta.

0 artigo também procura estimular a oxigenação dos estudos em torno do pensamento teórico do jovem Marx - um objeto que não esgotou seus problemas e interesses. Certa vez, perguntado se “'o ajuste de contas' com a dialética tem necessariamente de passar por Hegel, Feuerbach e pelo jovem Marx", José Arthur Giannotti respondeu um enfático "sim" (Giannotti, 2011, p.22). A perspectiva elaborada no artigo pretende ser uma contribuição nessa direção.

\section{Crítica positiva e a pressa do concreto}

Nos anos de 1830 e 1840, a marca da cultura filosófica alemã era o hegelianismo. É com Feuerbach que começam a aparecer as fissuras que colocariam em xeque a expectativa de simplesmente continuar ou completar o legado deixado por Hegel. 0 impacto de Feuerbach nesse contexto, com a sua autodenominada "filosofia nova" a "filosofia do futuro", conforme anuncia o artigo de 1843 (Feuerbach, 1988, p.15) -, sobre parte da esquerda hegeliana é largamente documentado (Cf. Breckman, 1999; Giannotti, 1966). Marx não passou incólume.

De fato, Marx logo comentaria que a "crítica da economia política deve, além do mais, assim como a crítica positiva em geral, sua verdadeira fundamentação às descobertas de Feuerbach" (Marx, 2004, p.20/317). ${ }^{2} 0$ conceito da crítica positiva remonta à crítica feuerbachiana à Ciência da lógica de Hegel, especialmente à concepção idealista e dialética do ser. Segundo Feuerbach, o ser que aparece no

\footnotetext{
1 Esses manuscritos compõem apenas parte dos chamados Cadernos de Paris, em que Marx registrava, anotava e desenvolvia reflexões próprias, nem sempre contínuas tematicamente ou consistentes entre si. Sobre as condições filológicas e editoriais desse material, cf. Musto, 2009.
}

2 A segunda paginação se refere à edição da MEGA², 1982. 
início da exposição da lógica hegeliana - o “imediato indeterminado" (Hegel, 2016, p.85) - é apenas o espelho negativo do pensamento que não sai de si para o objeto sensível. Nesse sentido, tudo que o pensamento nomeia fora de si consta apenas como o carente de pensamento, como falta de significado. Assim, prossegue Feuerbach, o ser aparece "não como o ser-outro do pensamento, mas como o pensamento do seroutro do pensamento" (Feuerbach, 2012, p.48). A incapacidade da lógica hegeliana em se abrir para seu outro radical resulta em que "o ser (o primeiro, o incondicionado) é revogado; revela-se como o não verdadeiro” (idem, p.40).

Para Marx, à primeira vista, a relevância da crítica positiva reside em que ela denuncia a mediação da lógica como heteronomia em relação a seus conteúdos materiais. Assim, a "posição [Position]”, argumenta Marx, "está ainda acometida pela sua oposição", o que tem para ele o resultado peculiar de que o positivo é justamente uma posição “não segura” de si (Marx, 2004, p.118/277). Nesse entendimento, o ser sensível, imediato, deve seu significado a algo abstrato e além dele. Dito de outro modo, o movimento dialético em Hegel poria o universal de tal modo que o resultado não poderia deixar de significar um rebaixamento da sensibilidade como esfera autônoma da vida humana e natural. Contudo, para Marx, o corolário hegeliano é a reconciliação dos opostos - forma universal abstrata e ser imediato - às expensas do último, transformado em uma expressão particular do universal, com o que se revelaria "a raiz do falso positivismo de Hegel ou de seu criticismo apenas aparente" (idem, p.130/299). Mas a relação entre Marx e a dialética hegeliana não se esgota na crítica positiva feuerbachiana.

\section{Abstração da forma, universalidade e dinheiro}

\section{a. Modernidade e determinação social da forma}

Para Feuerbach, o universal hegeliano é essencialmente teológico e filosófico o que o leva a propor como solução uma nova filosofia, ou uma "reforma da filosofia". Para Marx, contudo, o universal hegeliano é socialmente constituído - a rigor, é a modernidade que está em questão. ${ }^{3} \mathrm{O}$ universal em Hegel, por sua vez, liga-se à noção de forma. Pois a forma se apresenta como essência universal que se concretiza, em parte, mediante a ação subjetiva, o que, na leitura de Marx, significa a formação da consciência de si. Por isso Marx afirma que "a essência humana, o homem refere-se para Hegel = autoconsciência" (idem, p.125/294, trad. modificada). Nesse esquema, a autoconsciência é a particularização do universal que existe como forma.

Na maneira como o jovem Marx lê Hegel, o conteúdo daquela autoconsciência

3 Para Hegel, é a modernidade que fornece o horizonte máximo, ou mesmo inescapável, da filosofia. Sobre alguns aspectos desse ponto, cf. Habermas, 2002, p.24-25. 
é puramente formal, o que significa dizer que a atividade humana seria incapaz de se constituir e orientar por conteúdos senão no interior ou por referência à forma universal da qual ela representa a consciência posta. Trata-se de uma "essência não-objetiva, espiritualista" (idem, ibidem). Não é por outra razão que Marx diz, a esse respeito, que o "homem que reconheceu levar no direito, na política, etc., uma vida alienada, leva nesta vida alienada, enquanto tal, sua verdadeira [vida] humana" (idem, p.130/299). A política e o direito - e a economia, vale acrescentar - comparecem nessa observação como formas universais e abstratas.

Mas, ao contrário de Feuerbach, Marx admite que a totalidade hegeliana parte não de universais teológicos, e sim da constituição histórica da sociedade moderna, cujos modos de ação, instituições e consciência correspondentes conformam então figuras racionais, e não apenas empíricas. Ocorre que todas essas determinações sofrem uma reinterpretação decisiva por Marx, que acusa Hegel de tê-las hipostasiado em formas lógicas do pensamento puro. Marx chama a atenção para o fato de que, a partir das exigências da própria lógica hegeliana, a forma canibalizaria seus conteúdos; quer dizer, ela os subsume a si como condição de racionalidade do todo. Do ponto de vista hegeliano, sem a reconciliação entre o pensar e a coisa, a forma permaneceria universalidade abstrata, não objetiva, ao passo que o conteúdo não seria racional. Para Marx, porém, a reconciliação hegeliana mostra que a "atividade plena de conteúdo, viva, sensível, concreta, da auto-objetivação transforma-se, por isso, na sua mera abstração, a negatividade absoluta” (idem, p.133/302, trad. modificada). Essa negatividade volatiza a atividade, que perde seu potencial mínimo de significado autônomo, tornando-se "forma abstrata, carente de conteúdo" (idem, ibidem), do que se segue naturalmente que o seu conteúdo efetivo "só pode ser também um conteúdo meramente formal, produzido pela abstração de todo o conteúdo" (idem, trad. modificada). Trata-se aqui da imposição do significado racional das formas aos particulares subsumíveis. A conclusão que Marx tira dessa concepção hegeliana é que as formas universais "são, portanto, formas da abstração universais abstratas, pertencentes a qualquer conteúdo, e, consequentemente, tanto indiferentes a todo conteúdo" (idem, ibidem).

Com efeito, Karl Löwith notou bem o que se passava nessa transformação de formas sociais historicamente determinadas em uma lógica filosófica, ao comentar que Hegel concebe as "partes específicas de seu sistema como categorias ontológicas, à custa de sua forma real de existência” (Löwith, 2014, p.75). Não surpreende, pois, que o desfecho pareça ser que essas categorias ontologizadas terminem sendo "indiferentes a todo conteúdo determinado e por isso aplicado a qualquer um" (idem, ibidem). A culminação da voracidade formal da filosofia hegeliana se confirmaria para Marx no tratamento da natureza, que "tem, portanto, de se suprassumir a si mesma, porque já foi posta por ele [Hegel] como um ser em potência suprassumido" 
(Marx, 2004, p.137/418).

Para Marx, as noções de forma e universalidade por si sós não são problemáticas. O que é insatisfatório para ele é a maneira como Hegel desenvolve as condições para a realização da razão - o modo em que aquelas potências lógicas se devem instanciar, particularizando-se na mediação dos dados imediatos -, confirmando as formas universais historicamente pressupostas. Assim, se a dialética hegeliana representa uma crítica profunda da imediatidade, ela contudo fica aquém da capacidade de crítica das formas e da universalidade mesmas.

\section{b. Forma da síntese social e o conceito de dinheiro}

Nos Manuscritos econômico-filosóficos, a palavra-chave da crítica é abstração (cf. Arthur, 1986, p.18). Um dos sentidos da palavra abstração é o de separação, isto é, abstrair é separar elementos que se apresentam ou deveriam se apresentar reunidos. De fato, Marx chega a dizer que, para o trabalhador, "a separação de capital, renda da terra e trabalho [é] mortal" (Marx, 2004, p.24/190). Outro significado, mais sintético do que analítico, é fornecido, nos Excertos do livro de James Mill, pelo conceito de dinheiro. Com esse conceito, a crítica da abstração hegeliana dará um passo além da crítica positiva. Isso ocorre porque o dinheiro será definido por Marx como uma abstração universal que existe de fato e que, como tal, opera como síntese de objetos empiricamente diferentes. A respeito do dinheiro, Marx afirma:

A essência do dinheiro não consiste, em primeiro lugar, em que nele a propriedade é alienada, mas em que o movimento ou a atividade de mediação, o ato humano, social, mediante o qual os produtos dos homens se complementam mutuamente, é alienado e se torna a característica de uma coisa material exterior ao homem, o dinheiro (Marx, 2016, p.147).

Nessa passagem, o dinheiro aparece como figura objetivada da atividade mediadora do ser humano. Como tal, ele é definido como um "mediador estranho" (idem, p.148), o que para Marx sinaliza a exterioridade da mediação em relação aos indivíduos. Essa exterioridade determina que "objetos, separados desse mediador, perdem seu valor" (idem, ibidem). Marx anota então que os objetos só têm valor quando representam esse mediador (idem, ibidem). Como mediação alienada, o dinheiro se apresentará como uma forma de síntese social do que se acha separado na sociedade. Para justificar esse passo, porém, deve-se recorrer à caracterização que Marx faz da oposição entre duas correntes do pensamento econômico: a "moderna economia política" e a corrente do "sistema monetário" (idem, p.149).

A corrente monetarista é entendida por Marx como uma "crua superstição político-econômica” (idem, ibidem), pois, no limite, ela identifica imediatamente 
riqueza e metais preciosos, como se fosse a qualidade metálica do dinheiro, uma qualidade sensível, a responsável pelo seu significado de valor. A moderna economia política, em contraste, vê o dinheiro como "uma mercadoria como qualquer outra, cujo valor, portanto, como de qualquer outra mercadoria, depende da relação dos custos de produção com a demanda, concorrência e oferta, com a quantidade ou concorrência das outras mercadorias" (idem, ibidem). Marx então afirma que o monetarista parece ter razão ao objetar ao economista moderno que, em fim de contas, "o valor real da coisa é o seu valor de troca, e este existe, em última instância, em dinheiro, assim como este existe nos metais nobres, e que, portanto, o dinheiro é o verdadeiro valor das coisas" (idem, ibidem).

No entanto, essa caracterização não visa a dar razão a uma das escolas contra a outra. Nas palavras de Marx, os monetaristas mantêm uma "crua superstição político-econômica", o que significa que sua teoria não é correta. Já dos economistas modernos, é dito que eles "concebiam a essência do dinheiro em sua abstração e generalidade” (idem, ibidem). No lugar daquela crua superstição, Marx afirma que eles “põem a superstição refinada” (idem, ibidem). No limite, o que se está dizendo é que ambas as perspectivas teóricas são supersticiosas e não apreendem a realidade moderna. Ambas "possuem em essência uma raiz", de modo que a forma esclarecida e refinada da superstição "não leva a que se reprima totalmente a sua forma sensível bruta, porque ela não ataca a sua essência, mas apenas a forma determinada dessa essência” (idem, ibidem). Veja-se como Marx começa a delinear uma relação entre essência e aparência.

Muito embora Marx considere as nações mercantilistas "servas do fetiche [Fetischdiener] das moedas" (Marx, 2004, p.144/286, trad. modificada), afirmando que essas nações, paradoxalmente, ainda não são "nações do dinheiro consumadas" (idem, ibidem), o mais relevante para Marx é a unidade das perspectivas das escolas opostas. Sob esse ponto de vista, como se viu, trata-se de dois modos de superstição. Mas, se ambas as concepções científicas são supersticiosas, variando em grau de refinamento, elas não são idênticas. No mercantilismo, é sublinhada a determinação empírica da riqueza, que existe como real valor no dinheiro. Já na economia política inglesa, o que é enfatizado é o conteúdo como "essência do dinheiro". Sob este aspecto, Backhaus chama atenção para o fato de que Marx está interessado não na antinomia dessas correntes, mas "na unidade interna de posições aparente e diametralmente opostas” (Backhaus, 1997, p.413). Na verdade, são dois lados da mesma moeda. No caso da economia moderna, o trabalho que produz valor é a essência; no caso do mercantilismo a "forma determinada dessa essência", a existência empírica daquele valor, é o dinheiro. ${ }^{4}$

4 Subjaz a essa caracterização um motivo hegeliano: o monetarismo aparece como empiria sem essência, ao passo que o moderno pensamento econômico surge como essência não particularizada, 
A propósito do dinheiro, ele é fundamental para Marx por representar a particularização daquela "universalidade abstrata" que é a essência. Assim como em Hegel a essência deve se manifestar como existente, bem como este representar uma exposição da essência, o mesmo vale aqui para a relação entre trabalho produtor de valor e dinheiro em Marx. Sem o dinheiro, a forma universal da produção de valor permaneceria sem objetividade, sem força socialmente vinculante. Nesse sentido, sugere Marx: "Se o dinheiro é o vínculo que me liga à vida humana, que liga a sociedade a mim, que me liga à natureza e ao homem, não é o dinheiro o vínculo de todos os vínculos?" (Marx, 2004, p.159/436) É evidente, todavia, que Marx não atribui essa força vinculante à qualidade metálica do dinheiro - o erro do monetarista, fetichista da moeda. Mas também não basta definir a abstrata essência universal - o erro do moderno economista, que elevou para si "o trabalho a único princípio" (idem, p.93/377), sendo então um fetichista do trabalho. A qualidade sintética do dinheiro representa a unidade objetiva das duas dimensões. Nenhuma daquelas duas escolas, pois, consegue deduzir suas categorias centrais.

Mas por que os economistas não conseguem deduzir suas categorias? (idem, p.155-6/433) A resposta de Marx indica que o problema consiste em que eles não deduzem o seu ponto de partida, pois a economia política parte da "relação do homem com o homem como a relação do proprietário privado com o proprietário privado" (Marx, 2016, p.153). É preciso ter em mente que Marx não está sugerindo que se devesse partir da relação entre seres humanos. Pelo contrário, ele admite que os economistas partem da "relação real" (idem, p.158). Ocorre então que a não dedução daquele pressuposto da economia política impede a dedução da função socialmente sintética do dinheiro. Com isso, a função monetária de síntese - a equivalência dos diferentes - parece natural ou acessória, mas não socialmente condicionada. A ideia de um equivalente universal e abstrato como forma sintética parece remontar à crítica madura da economia política, mas ela já está contida nos escritos de juventude como desenvolvimento inicial (cf. Jappe, 2014).

Em ambos os lados aparece, então, a propriedade privada como representante de uma propriedade privada de outra natureza, como o igual de um produto de outra natureza, e ambos os lados se relacionam um com outro de tal modo que cada um representa a existência de seu outro e ambos se relacionam um com outro mutuamente como substitutos de si mesmo e de seu outro. A existência da propriedade privada enquanto tal se tornou, portanto, um sucedâneo, um equivalente. [...] Enquanto equivalente, sua existência não é mais a que the é própria. Ela se tornou valor e, de modo imediato, valor de troca. Sua existência enquanto valor é uma existência distinta de sua existência imediata, exterior à sua essência específica, uma determinação alienada de si própria, apenas uma existência relativa dela (Marx, 2016, p.154).

isto é, sem objetividade. Seriam assim concepções unilaterais. Sobre o lado do trabalho que produz valor como essência, cf. Serrano, 2016. 
Ora, isso significa que a economia política, ao partir da relação moderna de propriedade, objetiva ao mesmo tempo essa relação social na forma do dinheiro. Isso só acontece, de acordo com Marx, porque tal forma de síntese é alienada ao que é sintetizado como equivalente. "O equivalente", diz Marx, "adquire sua existência como equivalente no dinheiro" (idem, p.156). "Não é difícil reconhecer”, Backhaus comenta o argumento, que Marx "está falando aqui sobre o dinheiro que em 'suas' funções opera como um sujeito 'inumano', nomeadamente, ele transforma coisas desiguais em iguais", do que se segue que as "leis independentes das coisas, de coisas 'fora do homem', apresentam o momento 'objetivo', ou mercantilista, da economia" (Backhaus, 1997, p.413). O outro momento objetivo concerne à essência do dinheiro, a saber, o trabalho como "essência subjetiva da propriedade privada" (Marx, 2004, p.103/386; cf. Arthur, 1986, p.28). De fato, trata-se de uma unidade de forma e conteúdo.

De modo geral, o que não é deduzido pela economia política é a moderna relação entre proprietários cujas atividades - separadas e privadas - pressupõem-se reunidas na forma monetária da troca de mercadorias. Essa relação social pressuposta contém, do lado da essência subjetiva, o trabalho alienado; do lado da essência objetiva, o dinheiro como forma de existência aparente daquela essência subjetiva. A dedução dessas categorias e formas conduz Marx à crítica daquele pressuposto social que torna aquelas mesmas categorias e formas representações científicas, isto é, descrições corretas da realidade social da produção capitalista. ${ }^{5}$ Desde o princípio, portanto, pode-se notar que Marx associa a crítica da economia política à crítica da sociedade, o que é bastante diferente da ideia de construir uma teoria econômica alternativa ou superior àquelas que ele começava a estudar nos anos 1840 .

\section{Reabilitação crítica da dialética}

\section{a. Economia política e idealismo, dinheiro e lógica}

Vimos que a economia política - igualmente em suas versões modernas e mercantilistas - produzia teorias que Marx classificou como superstições mais ou menos refinadas. Ora, mas se a economia política parte da "relação real", e se é ao mesmo tempo uma superstição, então a superstição existe realmente. De hábito, o que se entende por "superstição"? Desde o iluminismo, o principal exemplo são as religiões. Essas seriam supersticiosas porque supõem que entidades espirituais interferem na realidade mundana e material, consistindo de um modo de causação metafísico no sentido mais literal. Quando Marx afirma a correção das representações

5 É por serem essas descrições corretas, operacionais, que Marx não pode seguir Feuerbach e propor algo como uma reforma do pensamento econômico. 
econômicas ao mesmo tempo em que as assume como superstições, o que ele está sugerindo, à primeira vista, é que a sociedade moderna é dirigida por modos não imediatamente materiais de causação. Com efeito, essa perspectiva de Marx aproxima muito a organização da sociedade burguesa ao modo como ele mesmo definiu a filosofia hegeliana. Afinal, esta era vista como uma imposição heterônoma da forma abstrata da universalidade sobre as singularidades vivas.

Marx estabelece, pois, uma relação muito íntima entre a crítica da economia política e a crítica do idealismo hegeliano. Na minha hipótese, as duas críticas não apenas coexistem, mas perfazem na gênese uma relação interna. É em virtude disso que Marx afirma que "Hegel se coloca no ponto de vista dos modernos economistas políticos" (Marx, 2004, p.124/405). Nesta perspectiva, Backhaus assinala o que ele denomina as "estruturas isomórficas dos objetos ontoteológicos e social-metafísicos, ou das estruturas isomórficas dos objetos políticos e econômicos” (Backhaus, 1997, p.413). Que haja isomorfia entre o idealismo e a economia política, isso significa que a forma em um caso se comporta de modo afim em outro.

Como se pode entender essa isomorfia entre economia capitalista e idealismo? No início desta discussão, vimos que Marx, comentando os méritos da crítica de Feuerbach, caracterizava a dialética de Hegel como um movimento no qual o universal, particularizando-se, subsumia o singular. Do ponto de vista lógico, como resultado, o singular não subsiste em si mesmo, mas apenas como dependente de seu outro. A particularização do universal representa uma posição do último no regime do ser, posição esta que captura o singular ao mesmo tempo em que o introduz na teia de significação racional da forma universal. Convém lembrar que o universal do qual se parte naquele movimento não é arbitrário, mas representa formas constitutivas da modernidade. Mas o que isso quer dizer?

Marx enxerga na sociedade burguesa uma forma cuja universalidade estabiliza e reproduz a totalidade social. Essa forma é o dinheiro. Sob atuação da síntese monetária, dado o pressuposto social das atividades privadas, a agência é motivada por interesses mercantis de todos os lados: "A medida do poder sobre teu objeto que atribuo ao meu precisa, no entanto, para se tornar um poder efetivo, do teu reconhecimento" (Marx, 2016, p.158). No contexto da troca mercantil, mediada pelo dinheiro, o reconhecimento entre os agentes não é dado pela relação recíproca entre suas carências e capacidades, e sim pela quantidade em que a forma-dinheiro existe, pois é esta forma que estabelece a síntese social de capacidades, carências e indivíduos entre si na sociedade capitalista.

Como mero homem, tua demanda é, sem esse instrumento, uma aspiração insatisfeita de tua parte, uma ocorrência inexistente para mim. Tu, enquanto homem, não está, portanto, em relação com meu objeto, pois eu mesmo não tenho uma relação humana com ele (idem, p.159). 
Nesse sentido, a relação entre os agentes e seus respectivos objetos é subsumida à forma do dinheiro, isto é, ao valor. 0 objeto que se encontre fora do alcance daquela forma não é reconhecido como objeto racional. Isolado como mera singularidade, ele não goza de efetividade - condicionada pela forma universal vigente. Nos Manuscritos, Marx dá uma representação muito contundente do desprezo em que o vivido se acha quando está fora do alcance dessa forma abstrata e universal. Comentando o modo como a economia política considera o ser humano em seu tempo livre - entendido como espaço possivelmente não mediado pelo valor -, Marx diz que ela não considera esse ser humano como tal, "mas deixa, antes, essa consideração para a justiça criminal, os médicos, a religião, as tabelas estatísticas, a política e o curador da miséria social" (Marx, 2004, p.30/248). Portanto, segundo Marx, a imposição que ocorre da forma do universal sobre o singular, na lógica hegeliana, é afim - isomórfica, utilizando a expressão de Backhaus - àquela que ocorre, na sociedade, da forma do dinheiro sobre os indivíduos. É isso que Marx quer dizer quando faz a reveladora associação: "A lógica - o dinheiro do espírito, o valor do pensamento, o [valor] especulativo do homem e da natureza" (idem, p.120/402), ainda designando o dinheiro como "espírito efetivo de todas as coisas" (idem, p.159/436, trad. modificada).

Como se pode notar, a aproximação entre economia política e dialética idealista se faz também porque a forma do universal e o dinheiro designam, a um só tempo, formas de dominação social. O que Marx está começando a desenvolver, com o seu projeto de crítica da economia, é o conceito de valor como dominação social.

Aquilo que [contava] como a dominação da pessoa sobre a pessoa é agora a dominação universal da coisa sobre a pessoa, do produto sobre o produtor. Assim como a determinação da alienação da propriedade privada já residia no equivalente, no valor, do mesmo modo o dinheiro é a existência sensível e mesmo objetiva dessa alienação (Marx, 2016, p.156).

Que o dinheiro, como forma existente da dominação da forma de equivalência sobre os conteúdos singulares, tenha uma ligação interna com o universal hegeliano é, mais uma vez, verificado nos Manuscritos, mais claramente no fragmento intitulado [Dinheiro], aliás muito pouco comentado na literatura. Aqui, Marx afirma que enquanto "tal mediação, o dinheiro é a força verdadeiramente criadora" (Marx, 2004, p.160/437). Essa força "verdadeiramente criadora", tal como o universal na lógica hegeliana, sublinha o poder real que a forma exerce sobre os conteúdos que ela subsume a si. Em uma passagem que atesta a reabilitação crítica da dialética hegeliana - no mesmo sentido da economia política -, Marx afirma que o “dinheiro - enquanto exterior, não oriundo do homem enquanto homem, nem da sociedade humana enquanto sociedade -, meio e capacidade universais, faz da representação efetividade e da efetividade uma pura representação" (idem, p.160/437-8). 
O que Marx está deixando claro aqui é que essa forma abstrata que domina seus conteúdos existe realmente no dinheiro, consumando a realidade da superstição econômica socialmente gerada. Essa existência abstrata transforma a representação em efetividade, afirmação que escandalizaria a antropologia positiva de Feuerbach. Mas este é exatamente o caso, o que leva Marx a definir o dinheiro como "conceito existente e atuante do valor" (Marx, 2004, p.160/438). Ele está chamando a atenção para um conceito que existe por meio do dinheiro, que, como tal, é a atuação do valor. Assim, pode-se dizer que o conceito completo do valor não é nem o trabalho produtor de valor - a essência abstrata nos economistas modernos -, nem tampouco o dinheiro como peça metálica - a forma de existência do valor nos monetaristas. Pelo contrário, o conceito é a unidade desses dois lados: é a essência existindo, aparecendo. Portanto, trata-se de uma abstração que é criada e se instancia na sociedade, sintetizando suas partes em uma totalidade assim como, segundo Marx, ocorre na filosofia hegeliana de modo lógico-ontológico. Nesse sentido, o dinheiro designa a atuação real de uma conceitualidade - o valor -, o que Patrick Murray percebeu bem, ao notar que "por meio dessa lente, não apenas as abstrações dinheiro e lógica dominam o vivo e sensível mundo humano; elas parecem tê-los criado. Este é o padrão lógico da prova ontológica segundo o qual o logos se fez carne" (Murray, 1988, p.49).

\section{b. Marx, crítico dialético da sociedade capitalista}

Ao assumir que a economia e o idealismo partilham uma mesma lógica e, ainda, que essa lógica descreve o processo real, Marx realça que a abstração não é um erro da razão idealista, mas o espelhamento acrítico de uma realidade ela mesma dominada por abstrações. Trata-se, como vimos, da raiz do positivismo do idealismo de Hegel. Mas qual é a razão desse positivismo? Segundo Marx, Hegel atribui às contradições e limitações sociais um grau variado, mas efetivo, de racionalidade, tendo para tanto ontologizado formas sociais históricas. O grande idealista não teria desconfiado o suficiente da própria razão. Nesse particular, tudo se passa como se a lógica capitalista do dinheiro fosse o pressuposto recalcado da dialética hegeliana, sendo o sintoma desse recalcamento filosófico o comportamento voraz e violento da forma sobre seus conteúdos. Com isso se reproduziria, no pensamento e de modo acrítico, a violência da realidade social capitalista sobre os indivíduos socializados.

Desse ponto de vista, a crítica de Marx a Hegel implica uma visão diferente acerca da modernidade. Essa questão nos permite introduzir um significado importante, até agora implícito, do conceito de dinheiro em Marx. Comentando suas diferentes concepções, especificamente sobre a economia capitalista, Richard Winfield afirma que Hegel 
elabora a estrutura total das relações mercantis sem subsumi-las a um sistema de capitais cujos lucros derivam do trabalho assalariado produtor de mercadorias. Embora Hegel faça a breve menção sobre a relação entre capital e trabalho, ele a trata como um elemento subordinado dentro da economia de mercado. Em contraste com Marx, ele não a vê como uma estrutura privilegiada de determinação que reveste e ordena todas as relações mercantis dentro de seu processo de acumulação de capital (Winfield, 1988, p.99).

É preciso ter em mente, seguindo Winfield, que o dinheiro interessa a Marx na medida em que ele é fundamental na acumulação do capital - isto é, quando o dinheiro integra a circulação do capital, não operando como simples meio de troca no mercado. Esse aspecto contribui para pormenorizar ainda mais a crítica de Marx a Hegel. Isso porque a observação de Winfield sobre a ausência do conceito de capital na concepção de Hegel deve ser lida à luz da maneira como o jovem Marx interpreta a dialética idealista. Disso resulta que, se a teoria hegeliana é capaz de explicitar as trocas que ocorrem no mercado, ela sublima a sistematicidade dessas trocas no próprio funcionamento de sua lógica dialética. Assim, a lógica idealista representaria, em regime filosófico, a função subordinante do capital no sistema das trocas mercantis. Como tentei mostrar, sem, no entanto, extrair todas as consequências que agora indico, essa ideia está contida na interpretação de Marx segundo a qual Hegel se encontra no ponto de vista da economia política. Murray o percebeu bem, ao afirmar que Marx entende Hegel como um "filósofo do capital":

o "do" neste caso ["filósofo do capital"] significa que Hegel expressava involuntariamente em sua lógica do conceito - e mais particularmente da ideia - a lógica do capital de subsunção da natureza e da humanidade. Ter o capital no cérebro não requereu a Hegel levar adiante uma exposição do capital e suas consequências (Murray, 2009, p.186). ${ }^{6}$

Isso significa que Marx compreende a filosofia de Hegel como a transfiguração filosófica de uma relação socialmente constituída, relação esta que não é conscientemente refletida por Hegel, mas opera como um modelo discreto de sua dialética. É nesse sentido que argumenta ainda Murray: “A partir da lógica do idealismo absoluto de Hegel, Marx esboça a lógica do capital” (idem, 1988, p.46). Ao enfatizar a lógica da forma-dinheiro do capital como modelo discreto da lógica da dialética hegeliana, Marx teria indicado o momento de verdade e de falsidade do próprio idealismo, delimitando o seu espaço de validade histórico e social. 0 mesmo se passa com a dialética. É nesta chave que se deve entender a crítica de Marx segundo a qual Hegel "encontrou a expressão abstrata, lógica, especulativa

6 Adorno havia intuído, mas não desenvolvido, essa chave de leitura da crítica de Marx a Hegel. Ao comentar a hipóstase de que se nutre a filosofia hegeliana, ele diz que "o factum brutum, que desaparece na totalidade do conceito de Espírito, retorna nele sob a forma da coerção lógica, a qual o particular não pode evitar, assim como o indivíduo não pode evitar a contrainte sociale" (Adorno, 2007, p.94). 
para o movimento da história", enfatizando ainda que essa expressão depende de sua validade social, isto é, vale para a "história ainda não efetiva do homem como sujeito pressuposto" (Marx, 2004, p.118/277), na medida em que o pressuposto são ainda as formas universais, abstratas e negativas de síntese social - entre as quais, por exemplo, o dinheiro.

Essas observações nos conduzem ao conceito de crítica. Pois o estatuto da crítica que Marx passa a elaborar no contexto de formação de sua crítica da economia política é incompreensível se não se tem em mente a isomorfia por ele vislumbrada entre a lógica da forma-dinheiro do capital e a lógica do idealismo hegeliano. É esse entrelaçamento, essa natureza quase gêmea, que qualifica a crítica do próprio idealismo, na medida em que a abstração no coração da dialética idealista não é compreendida como um mero engano ou incorreção cognitiva, mas como socialmente constituída pela modernidade capitalista. ${ }^{7}$ A crítica do idealismo e a crítica da economia política se alimentam reciprocamente no discurso marxiano. Além disso, a crítica não pode simplesmente afirmar a correção da realidade contra a incorreção das abstrações do pensamento, pois, como vimos, a realidade mesma é essencialmente mediada por formas abstratas. Essa concepção da crítica lhe confere uma qualidade dialética, que passa a incluir, entre seus significados, o de dominação.

No entanto, essa dialética não suprime o momento por assim dizer feuerbachiano - a expectativa de que o particular sensível possa existir livre de dominação -, mas o reinterpreta de acordo com as exigências dialéticas da crítica das "estruturas isomórficas" entre economia e idealismo. ${ }^{8}$ Aquele momento se mantém presente como função crítica, tal como se evidencia na afirmação de Feuerbach segundo a qual "nos libertaremos de tal contradição se fizermos do real e do sensível o sujeito de si mesmo" (Feuerbach, 1988, p.65). Isso significa dizer que a dialética não se esgota no reconhecimento da mediação - o que, de resto, a filosofia hegeliana sempre garantiu. Se ela não ultrapassasse esse limite, dificilmente se poderia dizer que ela seria apta a constituir uma crítica. A dialética é crítica, para Marx, porque a realidade da produção social capitalista exibe a mediação da forma como violência da abstração sobre sua matéria viva e natural. É nesse sentido que Marx diz que a "efetivação do trabalho tanto aparece como desefetivação que o trabalhador é desefetivado até morrer de fome" (Marx, 2004, p.80/365). Ora, se a forma universal era condição de racionalidade - tanto para a economia política como para o idealismo - , Marx mostra que a totalidade constituída pelas formas universais do dinheiro e do capital

7 Acerca da complexa relação que Marx trava, em sua juventude, com a dialética hegeliana, cf. Colletti, 1975.

8 A presença de Feuerbach na reflexão de Marx, sobretudo em sua juventude, certamente é mais complexa. Esclarecê-la requereria tratar dos conceitos de alienação, ser genérico e naturalismo, bem como das peculiares acepções de comunismo e socialismo empregadas pelo autor nesse contexto. No entanto, isso teria me levado longe demais. 
apontam, não para a realização da razão, mas para a autodestruição de suas partes vivas constitutivas.

A produção produz o homem não somente como uma mercadoria, a mercadoria humana, o homem na determinação da mercadoria; ela o produz, nesta determinação respectiva, precisamente como um ser desumanizado tanto espiritual quanto corporalmente (idem, p.92-3/249, trad. modificada).

Essa perspectiva revela que a constituição dessa totalidade implica a negação das partes imediatas e vivas de que a forma universal depende para se tornar efetiva. Segundo Marx, essa negação submete "o trabalhador à fome, ou o obriga a sujeitarse a todas as exigências” do “capitalista” (idem, p.24). Há duas afirmações implícitas aqui. De um lado, a negação se define como supressão da vida do corpo; de outro, ela se apresenta como não-liberdade. Se Marx seguisse Feuerbach e afirmasse a primazia do dado sensível como fundamento, ele perderia de vista a mediação em que o dado positivo se acha, com o que se produziria um ocultamento das formas de dominação que operam na sociedade como mediação da imediatidade. ${ }^{9}$

De fato, embora pareça excessivo empregar a expressão “teoria do valor” neste momento da obra de Marx, Backhaus sem dúvida tem razão ao dizer que a "teoria do valor, para Marx, era desde o princípio uma teoria do objeto econômico, e não apenas uma teoria da troca qua uma teoria da troca de atividades [Tauschhandlungstheorie]" (Backhaus, 1997, p.416). É claro, pois, que a troca é pensada por Marx desde o início como troca mercantil, isto é, como mediação histórica e social da forma-dinheiro do capital. Assim, o decisivo é que a concepção dessa forma universal de mediação permite a Marx reassumir criticamente a dialética, isto é, dar a ela, segundo suas intenções, uma função crítica da sociedade.

Assim se mostra, portanto, que o projeto inicial de crítica da economia em Marx encara a economia não como fundamento positivo da sociedade, mas como uma teoria dialética em que formas universais atuam como modos de dominação por meio de abstrações socialmente geradas. Ao deduzir aquelas formas, a mediação social é exposta como violência e não-liberdade social. Da dedução, pois, não emerge uma totalidade racional. Com isso a teoria dialética é simultaneamente crítica. Assim, a perspectiva de que singularidades sensíveis e indivíduos humanos possam de algum modo existir realmente como sujeitos é assumida como possibilidade por meio da superação da sociedade na qual essa perspectiva é negada. ${ }^{10}$

9 Interpretando a visada teórica da crítica de Marx, Colletti afirma: "O 'ponto de vista' não pode ser concreto quando seu objeto é 'abstrato'” (Colletti, 1975, p.33).

10 Trata-se, como formulou com clareza Ruy Fausto a respeito da filosofia da história elaborada nos Manuscritos, de uma antropologia negativa, isto é, de uma concepção da história como préhistória, ou história natural, em que o ser humano existe como pressuposto. Cf. Fausto 1980, p.9. 


\section{Consideração final}

As linhas da análise e da intepretação aqui desenvolvidas pretenderam indicar o significado da relação entre a crítica da economia política nos escritos de juventude de Marx e a sua crítica ao idealismo de Hegel. A ideia sustentada é a de que as duas críticas estão essencialmente imbricadas. Isso ocorre porque Marx entende as formas sociais da economia como modelo discreto da dialética hegeliana, especialmente quando aproxima o dinheiro à lógica. Esse modelo desenvolve uma relação entre universal e particular que, para Marx, constitui o núcleo do que deve ser criticado na realidade presente. Em uma palavra, Hegel deve ser criticado porque, no essencial, seu pensamento espelha a realidade. Essa realidade, porém, é ela mesma determinada de modo negativo, isto é, como dominada e constituída por formas abstratas de síntese social. Como resultado, tem-se uma crítica da filosofia de Hegel e do pensamento econômico cuja solução não consistirá nem na proposição de uma nova filosofia, nem na construção de uma nova ciência econômica. Pelo contrário, essa crítica demarca o campo de validade social da dialética, em cujo interior Marx procura reativar uma perspectiva crítica que possa, em registro teórico, desidentificar os conteúdos vivos em relação às formas socialmente sintetizadas pela produção capitalista.

\section{Referências}

Adorno, T. W. (2007). Três estudos sobre Hegel. Tradução de Ulisses Razzante Vaccari. São Paulo: Editora Unesp.

Arthur, C. (1986). Dialectics of labour: Marx and his relation with Hegel. Oxford: Basil Blackwell.

Backhaus, H-G. (1997). Dialektik der Wertform: Untersuchungen zur Marxschen Ökonomiekritik. Freiburg: Ça ira.

Breckman, W. (1999). Marx, the Young Hegelians, and the origins of radical social theory: dethroning the self. New York: Cambridge Press University.

Colletti, L. (1975). “Introduction”. In: Marx's Early Writings. New York: Penguin Books.

Fausto. R. (1980). Sobre o jovem Marx. Discurso, 1(13), pp.7-52.

Feuerbach, L. (1988). Princípios da filosofia do futuro e outros escritos. Tradução de Artur Morão. Lisboa: Edições 70.

- (2012). Para a crítica da filosofia de Hegel. Tradução de Adriana Veríssimo Serrão. São Paulo: LiberArs.

Giannotti, J. A. (1985). Origens da dialética do trabalho: estudos sobre a lógica do jovem Marx. $2^{\mathrm{a}}$ ed. Porto Alegre. . (2011). Entrevista com José Arthur Giannotti. Trans/Form/Ação, 34, 
Edição Especial, pp.15-23.

Habermas, J. (2002). O discurso filosófico da modernidade: doze lições. Tradução Luiz Sérgio Repa e Rodnei Nascimento. São Paulo: Martins Fontes.

Hegel, G. W. F. (2016). Ciência da lógica: 1. A doutrina do ser. Tradução Christian Iber et al. Petrópolis: Vozes / Ed. Universitária São Francisco.

Jappe, A. (2014). Alienação, reificação e fetichismo da mercadoria. Limiar, 1 (2), pp.4-29.

Löwith, K. (2014). De Hegel a Nietzsche: a ruptura revolucionária no pensamento do século XIX: Marx e Kierkegaard. Tradução de Flamarion C. Ramos e Luiz Fernando B. Martin. São Paulo: Editora UNESP.

Marx, K. (1982). Ökonomisch-philosophische Manuskripte. In: MEGA2 I.2: Werke, Artikel, Entwürfe. März 1843 bis August 1844. Berlin: Dietz Verlag, pp.323-438. . (2004). Manuscritos econômico-filosóficos. Tradução de Jesus Ranieri. São Paulo: Boitempo.

- (2016). Excertos do livro de James Mill “Éléments d'économie politique”. Tradução de Luiz Philipe de Caux. Cadernos de Filosofia Alemã, 21, (1), pp.147-161.

Murray, P. (1988). Marx's Theory of Scientific Knowledge. New Jersey: Humanities Press International.

. (2009). "Value, Money and Capital in Hegel and Marx". In: Chitty, A. e Mclvor, M. (orgs.). Karl Marx and Contemporary Philosophy. Londres: Palgrave Macmillan.

Musto, M. (2009). Marx in Paris: Manuscripts and notebooks of 1844. Science \& Society, 73(3), pp.386-402. Doi: 10.1521/siso.2009.73.3.386.

Rancière, J. (1979). "O conceito de crítica e a crítica da economia política dos Manuscritos de 1844 a 0 capital". In: Ler O capital. Tradução de Nathanael C. Caixeiro. Rio de Janeiro: Zahar.

Renault, E (org.). (2008). Lire les Manuscrits de 1844. Paris: PUF.

Serrano, B. (2016). Jovem Marx: crítica da economia política como crítica do trabalho. Peri, 8 (1), pp.45-61. Recuperado de: http://www.nexos.ufsc.br/index.php/ peri/article/view/1300/842. Acesso em: 02 nov. 2017.

Winfield, R. (1988). The Just Economy. New York/London: Routledge.

Recebido em: 07.11.2017

Aceito em: 13.04.2018 